\title{
Propofol attenuates cytokine-mediated upregulation of expression of inducible nitric oxide synthase and apop- tosis during regeneration post-partial hepatectomy ${ }^{1}$
}

Hatice Yagmurdur', Kenan Binnetoglu", Hesna Muzeyyen Astarci"l, Mahmut Can Yagmurdur'v

'Professor, Department of Anesthesiology and Reanimation, School of Medicine, Kafkas University, Kars, Turkey. Conception and design of the study; acquisition, analysis and interpretation of data; manuscript writing; critical revision.

"Assistant Professor, Department of General Surgery, School of Medicine, Kafkas University, Kars, Turkey. Design of the study, manuscript writing.

"'MD, Department of Pathology, Ministry of Health Ankara Research and Training Hospital, Ankara, Turkey. Acquisition, analysis and interpretation of data; manuscript writing.

'Vrofessor, Department of General Surgery, School of Medicine, Kafkas University, Kars, Turkey. Conception of the study, analysis and interpretation of data, manuscript writing, critical revision.

\section{Abstract}

Purpose: To determine the effects of propofol and ketamine anesthesia on liver regeneration in rats after partial hepatectomy (PHT).

Methods: Male Wistar albino rats were assigned randomly to four groups of 10. Anesthesia was induced and maintained with propofol in groups 1 and 2, and with ketamine in groups 3 and 4. PHT was undertaken in groups 1 and 3. Rats in groups 2 and 4 (control groups) underwent an identical surgical procedure, but without PHT. At postoperative day-5, rats were killed. Regenerated liver was removed, weighed, and evaluated (by immunohistochemical means) for expression of inducible nitric oxide synthase (iNOS), endothelial NOS (eNOS), apoptosis protease-activating factor (APAF)-1, and proliferating cell nuclear antigen (PCNA). Also, blood samples were collected for measurement of levels of tumor necrosis factor (TNF)- $\alpha$ and interleukin (IL)-6.

Results: Between groups 2 and 4, there were no differences in tissue levels of iNOS, eNOS, and APAF-1 or plasma levels of TNF- $\alpha$ and IL-6. eNOS expression was similar in group 1 and group 3. Expression of iNOS and APAF-1 was mild-to-moderate in group 1, but significantly higher in group 3. Groups 1 and 3 showed an increase in PCNA expression, but expression in both groups was comparable. Plasma levels of TNF- $\alpha$ and IL-6 increased to a lesser degree in group 1 than in group 3.

Conclusion: Propofol, as an anesthetic agent, may attenuate cytokine-mediated upregulation of iNOS expression and apoptosis in an animal model of liver regeneration after partial hepatectomy.

Key words: Propofol. Ketamine. Liver Regeneration. Hepatectomy. Anesthesia, Intravenous. Rats. 


\section{Introduction}

Hepatic regeneration after liver surgery is the primary factor that determines survival. Regulatory mechanisms of regeneration modulation are complex and multifactorial, and are not understood clearly ${ }^{1}$. Liver regeneration is dependent upon on the balance between the death and proliferation of cells ${ }^{2}$. Cell death can occur via necrosis or apoptosis ${ }^{3}$. Histopathologic studies of failed livers have shown significant apoptotic changes rather than cell necrosis ${ }^{4}$. Such findings have led researchers to study anesthetic agents in terms of liver protection and hepatocyte apoptosis.

Nitric oxide (NO) is an oxidant produced by nitric oxide synthase (NOS) in the liver. NO is known to have an important role in apoptosis or be beneficial to cell proliferation, according to its concentration ${ }^{5}$. NOS has been identified in several tissues, but only three isoforms (neuronal, inducible (iNOS), and endothelial (eNOS)) have been identified in mammals. eNOS and nNOS are expressed constitutively, and produce relatively small amounts of NO.

Propofol is the most widely used anesthetic drug administered via the intravenous route. Numerous studies based on models of ischemia-reperfusion injury have reported that propofol has antioxidant and antiinflammatory activity ${ }^{6,7}$. Ketamine is another commonly used anesthetic administered via the intravenous route, and has antioxidant properties in vitro ${ }^{8}$.

The present study aimed to determine the effects of propofol and ketamine anesthesia during partial hepatectomy (PHT) based on measurement of levels of the proinflammatory cytokines interleukin (IL)- 6 and tumor necrosis factor (TNF- $\alpha$ ). Also, we wished to determine the effects of propofol and ketamine anesthesia on the regenerative capacity of the liver after PHT using the cellular immunohistochemical (IHC) markers eNOS,
iNOS, apoptosis protease-activating factor (APAF)-1, and proliferating cell nuclear antigen (PCNA).

\section{- Methods}

Procedures in the present study were undertaken in accordance with the Guide for the Care and Use of Laboratory Animals (National Institutes of Health, Bethesda, MD, USA) and the Declaration of Helsinki.

The study comprised 40 adult male albino Wistar rats (250-330 g). Animals were housed eight per Plexiglas ${ }^{\mathrm{TM}}$ cage in a quiet room at $22 \pm 2{ }^{\circ} \mathrm{C}$ and humidity of $60 \pm 5 \%$ under a 12-h light-dark cycle (light from 07:00-19:00). Food and water were available ad libitum. All experiments were carried out between 09:00 and 11:00.

Rats were divided randomly into four groups of 10. Food was withheld $6 \mathrm{~h}$ before surgery, but water remained available. Anesthesia was induced using propofol (80 mg. $\mathrm{kg}^{-1}$, i.p.; Fresenius Kabi, Bad Homburg, Germany) in groups 1 and 2 , and using ketamine (20 mg. $\mathrm{kg}^{-1}$, i.p.; Pfizer, New York, NY, USA) in groups 3 and 4 . Anesthesia was maintained using an intravenous infusion via tail veins of the same drug used for the induction of anesthesia. PHT (50\%) was done in groups 1 and 3 . In groups 2 and 4 (control groups), an identical surgical procedure was undertaken but without PHT.

Surgery was carried out through a midline laparotomy incision. Intestines were packed with sterile sponges soaked in physiologic $(0.9 \%)$ saline at $37^{\circ} \mathrm{C}$. Ringer's lactate solution $(5 \mathrm{~mL})$ was injected into the peritoneal cavity to prevent dehydration during the surgical procedure. PHT (50\%) was done according to the Higgins and Anderson method for left lateral and median lobectomy ${ }^{9}$. After each surgical intervention, the incision was closed in layers. At the end of the experiment, 
animals were allowed to recover from anesthesia and allowed food and water ad libitum. At postoperative day (POD)5, animals were decapitated. The regenerated liver was removed and weighed. Then, it was sent to the pathology laboratory for IHC evaluation of eNOS, iNOS, APAF-1, and PCNA. Blood samples were also obtained for measurement of plasma levels of TNF- $\alpha$ and IL-6.

\section{Gravimetric analyses of the regeneration rate}

The rate of liver regeneration was calculated according to Becker's formula:

Liver-regeneration rate $(\%)=100 \times[C-(A-B)]$ $\div A$

where $A$ is the mean estimated wholeliver weight of a rat that underwent PHT (theoretically obtained from healthy controls), $B$ is the mean weight of liver tissue excised from the rat during $\mathrm{PHT}$, and $\mathrm{C}$ is the mean weight of the remnant livers at the time at which rats were killed $^{10}$.

\section{IHC evaluation}

Liver specimens were evaluated by independent pathologists in a blinded and numbered fashion. Liver regeneration after surgery was assessed by IHC analyses, as described previously ${ }^{11,12}$. Samples were embedded in paraffin, cut into sections of thickness $5 \mu \mathrm{m}$, and prepared for IHC staining (BioGenex, San Ramon, CA, USA). Sections were mounted on poly-L-lysine-coated slides and dewaxed in xylene. After washing in a series of ethanol solutions of decreasing concentration and water, sections were treated with cold $3 \%$ hydrogen peroxide $\left(\mathrm{H}_{2} \mathrm{O}_{2}\right)$ in distilled water for $30 \mathrm{~min}$ to block endogenous peroxidases. Sections were washed with phosphate-buffered saline (PBS) and incubated overnight at $4^{\circ} \mathrm{C}$ with an eNOS monoclonal (RB-1711-P; 1:100 dilution; Neomarkers, Fremont, CA, USA), iNOS polyclonal (RB-9242-P; 1:100; Neomarkers), or APAF-1 antibody (1/100; Neomarkers) for $16 \mathrm{~h}$ at $4^{\circ} \mathrm{C}$. Then, sections were incubated with biotinylated immunoglobulins for the corresponding primary antibody. Next, sections were washed with PBS thrice and incubated with an avidin-biotin-peroxidase complex. Peroxides were visualized by incubating sections in diaminobenzidine and $\mathrm{H}_{2} \mathrm{O}_{2}$. Negative controls were treated identically by omission of incubation with the primary antibody.

The three-step immunoperoxidase avidin-biotin-peroxidase complex method (Vectastain ${ }^{\circ}$ Elite; Vector Laboratories, Burlingame, CA, USA) was used to measure expression of PCNA (clone PC10; MS-106, 1:100 dilution; Neomarkers). PCNA was used to measure cell proliferation. From each rat, 1000 cells were evaluated and the PCNA labeling index (total number of labeled cells divided by the total number of cells counted and expressed as a percentage) recorded.

IHC staining and the number of immunopositive cells was evaluated semiquantitatively using a four-tiered scale for staining (0: negative; 1 : mild; 2 : moderate; 3 : marked) and cell number (1: $<10 \%$ positive cells; 2 : $10-50 \%$ positive cells; $3:>50 \%$ positive cells).

\section{Serum levels of TNF- $\alpha$ and IL-6}

Blood samples were collected from rat abdominal aortas for measurement of serum levels of TNF- $\alpha$ and IL- 6 using an enzymelinked immunosorbent assay kit (Biosource International, Camarillo, CA, USA). Levels are expressed as pg. $\mathrm{mL}^{-1}$.

\section{Statistical analyses}

Group data are the mean \pm SD. Quantitative analyses of mean values for serum 
levels of IL-6, TNF- $\alpha$ and liver regeneration rate were done using Kruskal-Wallis one-way analysis of variance (ANOVA) among groups. Paired comparisons of groups were made with the Mann-Whitney $U$-test to assess which group or groups were the reasons for the difference. Then, an error level of $\alpha=0.05$ was divided into the number of comparisons, and the Bonferroni correction made. IHC analyses for iNOS, eNOS, APAF-1, and PCNA were evaluated qualitatively by the $\chi^{2}$ test with Yates' correction factor. $p<0.05$ was considered significant.

\section{Results}

Mean hepatectomized liver weight and mean liver regeneration rates calculated by gravimetric analyses between groups 1 and 3 were not significantly different ( $p>0.05)$.

The mean plasma level (in pg. $\mathrm{mL}^{-1}$ ) of TNF- $\alpha$ was similar in control groups (group 2: $20.8 \pm 15.75$; group 4: $27.5 \pm 12.5$ ) but significantly different between similar anesthetic groups $(p<0.05)$. The mean plasma level (in pg. $\mathrm{mL}^{-1}$ ) of TNF- $\alpha$ of group 1 was 68.75 \pm 9.33 as compared with $20.8 \pm 15.75$ in group 2 $(\mathrm{p}<0.05)$. The mean plasma level (in pg. $\mathrm{mL}^{-1}$ ) of TNF- $\alpha$ in group 3 was $92.55 \pm 12.70$ as compared with $27.5 \pm 12.5$ in group $4(p<0.05)$.

The mean plasma level (in pg. $\mathrm{mL}^{-1}$ ) of IL-6 was similar in control groups (group 2: $4.5 \pm$ 10; group 4: $9 \pm 12.5$ ), but significantly different between similar anesthetic groups $(p<0.05)$. The mean plasma level (in pg. $\mathrm{mL}^{-1}$ ) of IL- 6 in group 1 was $27.05 \pm 5.26$ as compared with $4.5 \pm 10$ in group $2(p<0.05)$. The mean plasma level (in pg. $\mathrm{mL}^{-1}$ ) of IL-6 in group 3 was $72.63 \pm$ 10.11 as compared with $9 \pm 12.5$ in group 4 (p $<0.05)$.

At POD5, levels of TNF- $\alpha$ and IL- 6 increased, but were significantly lower in the propofol group (group 1) than in the ketamine group (group 3) $(p<0.05)$ (Table 1$)$.

Table 1 - Plasma levels (in pg.mL $\mathrm{L}^{-1}$ ) of TNF- $\alpha$ and IL-6 in study groups.

\begin{tabular}{llll} 
& $\begin{array}{l}\text { Group 1 } \\
\text { (propofol anesthesia) }\end{array}$ & $\begin{array}{l}\text { Group 3 } \\
\text { (ketamine anesthesia) }\end{array}$ & p \\
\hline TNF- $\alpha$ & $68.75 \pm 9.33$ & $92.55 \pm 12.70$ & 0.02 \\
IL-6 & $27.05 \pm 5.26$ & $72.63 \pm 10.11$ & 0.002 \\
\hline
\end{tabular}

Values are mean \pm SD.

IHC data suggested that expression of iNOS and eNOS was negative-to-mild in control groups and not significantly different between groups 2 and 4 ( $p>0.05)$. At POD5, marked expression of iNOS was observed in group $3(p<0.05)$. Also, increased expression of iNOS was accompanied by high levels of TNF- $\alpha$ and IL-6 in group 3. However, iNOS reactivity was mild-to-moderate in rats undergoing PHT under propofol anesthesia $(p<0.05)$. IHC analysis suggested that eNOS expression in rats undergoing $\mathrm{PHT}$ increased significantly compared with control sections at POD5 $(p<0.05)$. This tendency was maintained without significant differences between groups 1 and 3 ( $p>0.05$ ) (Figures 1 and 2).

Tissue sections from the livers of control animals IHC-stained for APAF-1 revealed very few stained hepatocyte nuclei. Remarkably increased APAF-1 immunostaining was observed in group 3, but only mild-tomoderate APAF-1 staining was observed in rats undergoing $\mathrm{PHT}$ under propofol anesthesia at POD5 ( $p<0.05$ ) (Figures 1 and 2). 
The PCNA expression used as a marker of cell regeneration was increased remarkably in rats that underwent PHT under propofol and ketamine anesthesia, but the difference

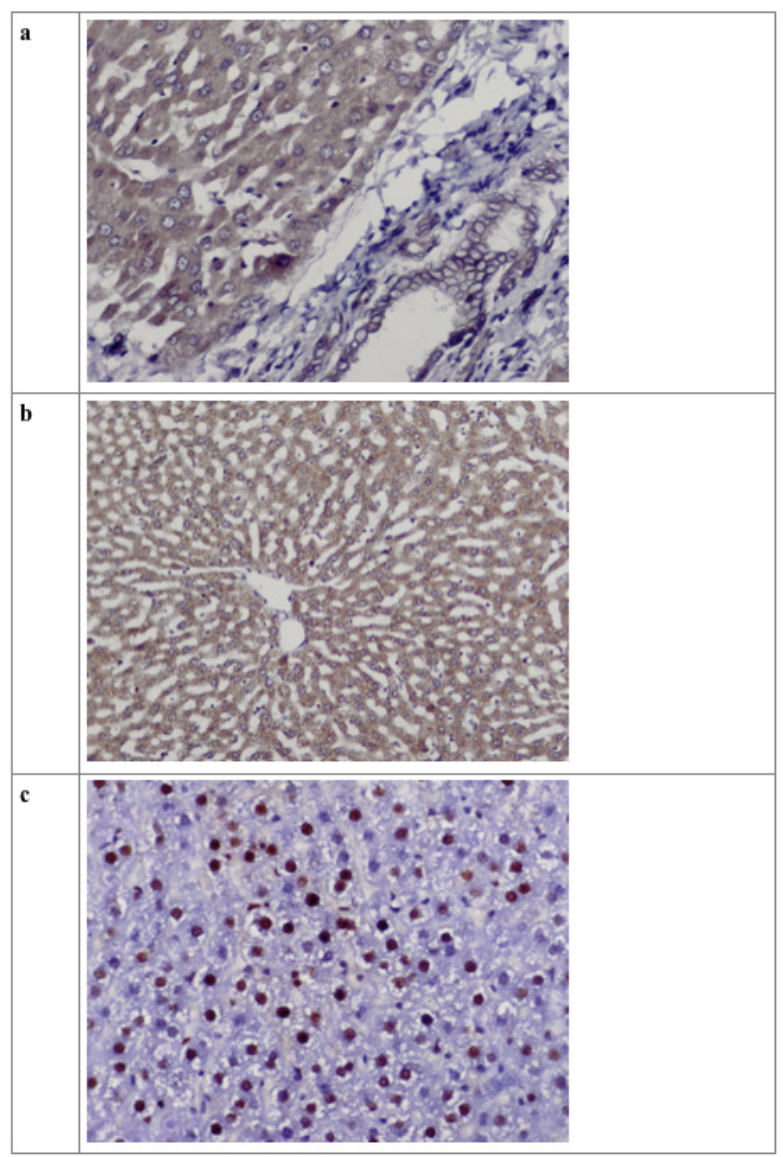

Figure 1 - Immunohistochemiscal findings of rats that underwent partial hepatectomy under propofol anesthesia. a. Mild-to-moderate iNOS expression (magnification, $\times 400$ ); b. Mild-to-moderate APAF-1 expression (magnification, $\times 200$ ); c. Marked expression of PCNA (magnification, $\times 400$ ).

\section{- Discussion}

The most important finding of the present study is that the increase in plasma levels of TNF- $\alpha$ and IL- 6 are in accordance with the upregulation of iNOS expression after PHT for a normal regenerative process. However, iNOS overexpression can have detrimental between study groups were not significant $(p<0.05$ for group 1 vs. group 2 and group 3 vs. group 4) ( $p>0.05$ for group 1 vs. group 3 ) (Figures 1 and 2).

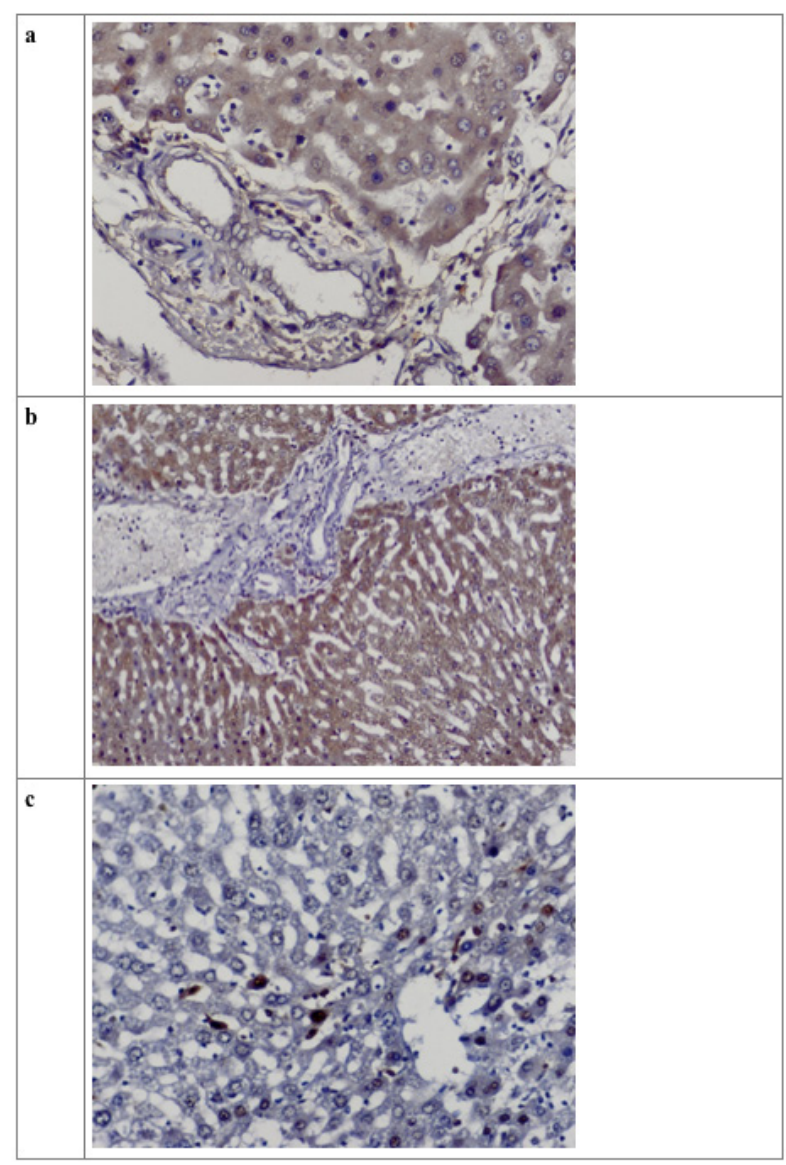

Figure $\mathbf{2}$ - Immunohistochemical findings of rats that underwent partial hepatectomy under ketamine anesthesia. a. Marked expression of iNOS (magnification, $\times 400$ ); b. Mmarked expression of APAF-1 (magnification, $\times 200$ ); c. Marked expression of PCNA (magnification, $\times 400$ ).

effects, including apoptosis. The anesthetic agent propofol reduced levels of TNF- $\alpha$ and IL-6 significantly, and APAF-1 expression (as a marker of the apoptotic index) downregulated iNOS expression in the liver 5 days after PHT.

Numerous studies have focused on hepatic ischemia-reperfusion injury and anesthetic agents in rats. However, data 
pertaining to the anti-apoptotic effects of anesthetic agents in a liver-regeneration model are lacking. The present study is an important addition to the literature because it shows that propofol has anti-apoptotic effects during liver regeneration.

Major resection of the liver has increased in safety with advancement of surgical methods. The regenerative capacity of the remnant liver is an important factor that determines survival ${ }^{3}$. The normal liver has regenerative capacity of $\leq 90 \%$ after $\mathrm{PHT}^{10,13}$. Hormones, growth factors, and pharmacologic agents are known to affect the regenerative capacity of the liver ${ }^{14}$. The present study analyzed two pharmacologic agents, the anesthetic agents propofol and ketamine, in terms of their effects on liver regeneration after PHT in rats. The regenerative effects of propofol and ketamine after PHT were not introduced entirely in in vivo studies.

Much of the research on changes in cytokine expression after hepatectomy has centered on serum levels of TNF- $\alpha$ and IL6 . These cytokines are usually associated with inflammation, and it is known that their expression increases after PHT at the acute phase of regeneration (from the first $5 \mathrm{~min}$ to 5-7 days) in rodents. TNF- $\alpha$ and IL-6 are also known to be priming factors for liver regeneration. Those features were our rationale for measuring levels of TNF- $\alpha$ and IL6 , and using those measurements as indicators of liver regeneration in our study.

Although liver regeneration after the loss of hepatic tissue is critical for the restoration of the homeostasis of the organ, the role of apoptosis is also as important as in proliferative process during liver regeneration. After PHT, residual hepatocytes enter into DNA synthesis to establish the original number of hepatocytes. A small wave of apoptosis of hepatocytes seen at the end of DNA synthesis suggests that this is a mechanism to correct an over-shooting of the regenerative response. The excess level of apoptosis that can cause necrosis and death of hepatocytes during this proliferative process also damages regeneration period of liver. Therefore, there must be a balance between proliferation and apoptosis. Evidence shows the importance of cytokines during liver regeneration. When a large piece of liver is removed by PHT, increased local expression of TNF- $\alpha$ triggers the production of another cytokine, IL-6, and both cytokines are required to initiate subsequent hepatocyte proliferation. iNOS is up-regulated in liver under a number of conditions, including ischemiareperfusion, acute damage by hepatotoxic agents, hepatites and liver regeneration in response to proinflammatory cytokines TNF- $\alpha$ and IL-6. Neither TNF- $\alpha$ nor IL- 6 alone are sufficient to activate iNOS transcription, but when these two cytokines are combined, upregulation occurs. iNOS is $\mathrm{Ca}^{+2}-$ independent, and synthesizes NO for extended periods of time, at high concentrations, serving as an important stimulus for apoptosis. Thus, the attenuation of both cytokine-mediated over upregulation of iNOS expression and excessive apoptosis are very important for the balance between proliferation and apoptosis during liver regeneration after $\mathrm{PHT}^{5}$.

Hepatocyte loss can occur due to necrosis or apoptosis. External signaling by the pro-inflammatory cytokine TNF- $\alpha$ is a known mechanism of apoptosis, and is associated with an increase in caspase- 3 activity and an increase in expression of the pro-apoptotic gene $B A X^{15}$. Rüdiger et $a l .{ }^{16}$ reported that an increased level of TNF- $\alpha$ has an apoptotic role in hepatic ischemia. The present study shows that TNF- $\alpha$ levels were higher in rats that underwent PHT in comparison with control groups. The TNF- $\alpha$ level in rats that underwent PHT under propofol anesthesia was significantly lower than in those that underwent PHT under ketamine anesthesia, suggesting that 
propofol might have a protective effect on the liver. These findings are in agreement with those of Abdel-Wahab et al. ${ }^{17}$, who reported attenuation of the TNF- $\alpha$ level and expression of apoptotic genes upon propofol infusion in ischemic livers.

In the present study, the level of another pro-inflammatory cytokine, IL-6, was also lower in rats that underwent PHT under propofol anesthesia compared with those that underwent PHT under ketamine anesthesia. IL-6 has an important role in initiation of the acute-phase response in hepatocytes, but does not have a direct mitogenic effect on hepatocytes ${ }^{18}$. It has been shown that the IL- 6 level increases after PHT and, even though this increase is important for the acute phase of regeneration, it is not an essential factor for continuation of the process ${ }^{19}$.

NO production is another important process associated with liver regeneration ${ }^{3,5}$. $\mathrm{NO}$ is derived from eNOS and iNOS ${ }^{20}$. In the liver, eNOS activity can be detected in the plasma membrane of rat hepatocytes and contributes to sinusoidal blood flow and portal perfusion. Increased expression of eNOS has been reported in models of liver disease such as cirrhosis ${ }^{21,22}$. In the present study, eNOS expression was increased but did not differ between study groups. Our results in these groups seemed to be in accordance with data reported in the literature.

Increased expression of iNOS has been reported to occur in inflammatory processes caused by cytokines such as TNF- $\alpha$, endotoxins, or bacterial lipopolysaccharides ${ }^{22,23}$. As such, PHT or ischemia-reperfusion injury may result in increased expression of iNOS ${ }^{24-27}$. The twosided effects of NO must be understood. A low concentration of NO may be cytoprotective and necessary for liver regeneration ${ }^{28,29}$, but a high concentration of NO may be toxic to hepatocytes ${ }^{30}$. Excess NO reacts with superoxide radicals to form peroxynitrite.
The latter damages cells by initiating lipid peroxidation $^{31}$. Rai et al. ${ }^{32}$ reported that iNOS has a role in apoptosis in a mouse model. Carnovale et $a .^{5}$ observed increased expression of iNOS in PHT rats and increased levels of BAX and p53 secondary to iNOS induction. It has been shown that BAX and p53 proteins are closely associated with apoptosis ${ }^{2,33}$. In the present study, iNOS staining was significantly more marked in rats that underwent PHT than in those that did not. More importantly, in rats that underwent PHT under propofol anesthesia, there was less iNOS staining than in those that underwent PHT under ketamine anesthesia. Dikmen et al. $^{34}$ reported that ketamine does not reduce iNOS-mediated NO production upon renal injury in unilateral ureteral obstruction. Those findings suggest that propofol might limit iNOS overexpression and exhibit an anti-apoptotic profile. Wang et al. ${ }^{35}$ reported that propofol had anti-apoptotic effects on hepatic LO2 cells exposed to oxidant stress induced by $\mathrm{H}_{2} \mathrm{O}_{2}$, and was mediated by activated kinase pathways. In accordance with those authors, our results suggest that propofol decreases the overexpression of iNOS as an anesthetic.

Because of our limited laboratory facilities, we did not evaluate the apoptosis with Western Blot analysis. Instead, we used APAF-1 which is a130-kDa protein that has a central role in the intrinsic or mitochondrial pathway of apoptosis. The oligomerization of pro-apoptotic proteins (Bax, Bak, Bad, BNIP3) into the outer mitochondrial membrane leads to the formation of pores, and results in mitochondrial release of cytocrhome c. The association of cytochrome $c$ with an adapter molecule, APAF-1, and caspase 9 in the cytoplasm activates the latter, which in turn, activates downstream caspases, ultimately resulting in hepatocyte apoptosis following $\mathrm{PHT}^{5}$. In response to apoptotic stimuli (e.g., increases in levels of reactive 
oxygen metabolites or NO), APAF-1 is released and a mitochondrial apoptosis pathway is activated $^{36,37}$. Data focusing on the effects of anesthetic agents on APAF-1 in a liver model are lacking. In our previous study, APAF-1 was analyzed in a testicular ischemia-reperfusion model. We noted non-high numbers of apoptotic cells in rats undergoing testicular ischemia-reperfusion under propofol anesthesia $24 \mathrm{~h}$ after reperfusion ${ }^{38}$. Findings of APAF-1 expression in the present study are in accordance with those of our earlier study. In the present study, APAF-1 expression differed significantly: APAF-1 expression was mild in rats that underwent PHT under propofol anesthesia compared with those that underwent PHT under ketamine anesthesia.

Several IHC methods have been used to assess liver regeneration. The most common method is that using PCNA ${ }^{39}$. PCNA levels in our study were increased in rats that underwent PHT under propofol and ketamine anesthesia, but the difference between groups was not significant. PCNA is a useful marker for monitoring progression of liver regeneration after hepatectomy ${ }^{40}$. In the present study, the increase in PCNA levels observed in rats that underwent PHT under propofol and ketamine anesthesia appear to be consistent with the literature.

Propofol is an effective anesthetic with potential antioxidant properties that can be delivered via the intravenous route. It has a chemical structure similar to that of phenol-based free radical-scavengers (e.g., vitamin E) and scavenges free radicals ${ }^{6,7}$. The mechanism underlying the hepatoprotective effect of propofol may be explained by the results of studies demonstrating that propofol can produce non-anesthetic organ-protective effects. The latter include: reduction of the generation and scavenging of free radicals; inhibitory effects on calcium channels and reduction of intracellular calcium overload; reduction of the chemotaxis of inflammatory cells; reduction of NO production and apoptosis by downregulation of iNOS expression ${ }^{34,38}$. The antioxidant activity of propofol may mediate its potential role as a modulator of apoptosis $^{41}$. Also, reduction in levels of TNF- $\alpha$ and caspase-3, with an increased BclxL/Bax ratio observed in the present study, probably contributed to the protective effect of propofol on hepatic ischemic-reperfusion injury in rats. In our study, reduced cytokine-mediated upregulation of iNOS expression and apoptosis during regeneration post-PHT by propofol anesthesia seems to be in accordance with the literature.

We selected ketamine due to its antioxidant properties in vitro to compare the effect of propofol on hepatic regeneration after $\mathrm{PHT}^{8}$. Our findings that ketamine does not reduce cytokine-mediated upregulation of iNOS expression after PHT is not in accordance with studies reporting the inhibitory effect of ketamine on iNOS-mediated NO release from alveolar macrophages in response to lipopolysaccharide in vitro ${ }^{42,43}$. The effect of ketamine on iNOS expression in vivo may, therefore, be a result of additional mechanisms than those suggested by in vitro experiments, and further study in this area is merited.

The most important limitation of our study was a lack of an anesthesia-free (negative control) group. This absence was because of the ethical impossibility of carrying out this type of surgical intervention in rats without anesthesia.

\section{Conclusions}

In in response to pro-inflammatory cytokines such as IL-6 and TNF- $\alpha$, iNOS expression is upregulated and induces apoptosis in hepatocytes during regeneration post-PHT in rats. Propofol, as an anesthetic delivered via the intravenous route, may 
attenuate cytokine-mediated upregulation of iNOS expression and apoptosis in an animal model of liver regeneration post-PHT. This protective effect of propofol, based on the observed anti-apoptotic and anti-inflammatory effects, may prove to be a promising approach if it is used as an anesthetic agent for liver surgery.

\section{References}

1. Fausto N. Liver regeneration. J Hepatol. 2000;32(1 Suppl):19-31. PMID: 10728791.

2. Kren BT, Trembley JH, Krajewski S, Behrens TW, Reed JC, Steer CJ. Modulation of apoptosis-associated genes bcl-2, bcl-x, and bax during rat liver regeneration. Cell Growth Differ. 1996;7(12):1633-42. PMID: 8959331.

3. Helling TS. Liver failure following partial hepatectomy. HPB (Oxford). 2006;8(3):16574. PMID: 18333270.

4. Takeda K, Togo S, Kunihiro O, Fujii Y, Kurosawa H, Tanaka K, Shimada H. Clinicohistological features of liver failure after excessive hepatectomy. Hepatogastroenterol. 2002;49(44):354-8. PMID: 11995449.

5. Carnovale CE, Ronco MT. Role of nitric oxide in liver regeneration. Ann Hepatol. 2012;11(5):636-47. PMID: 22947523.

6. Murphy PG, Myers DS, Davies MJ, Webster $\mathrm{NR}$, Jones JG. The antioxidant potential of propofol (2, 6-diisopropylphenol). $\mathrm{Br} \mathrm{J}$ Anaesth. 1992;68(6):613-8. PMID: 1319189.

7. Runzer TD, Ansley DM, Godin DV, Chambers GK. Tissue antioxidant capacity during anesthesia: propofol enhances in vivo red cell and tissue antioxidant capacity in a rat model. Anesth Analg. 2002;94(1):89-93. PMID: 11772807.

8. Weigand MA, Schmidt $H$, Zhao Q, Plaschke K, Martin E, Bardenheuer HJ. Ketamine modulates the stimulated adhesion molecule expression on human neutrophils in vitro. Anesth Analg. 2000;90(1):206-12. PMID: 10625005.

9. Higgins GM, Anderson RM. Experimental pathology of the liver: Restoration of the liver of the white rat following partial surgical removal. Arch Pathol. 1931;12:186202. PMID: 10005251121.
10. Okano T, Ohwada S, Nakasone $Y$, Sato Y, Ogawa T, Tago K, Morishita Y. Blood transfusion causes deterioration in liver regeneration after partial hepatectomy in rats. J Surg Res. 2001;101(2):157-65. PMID: 11735271.

11. Hall PA, Levison DA, Woods AL, Yu CC, Kellock DB, Watkins JA, Dover R. Proliferating cell nuclear antigen (PCNA) immunolocalization in paraffin sections: An index of cell proliferation with evidence of deregulated expression in some, neoplasms. J Pathol. 1990;162(4):285-94. PMID: 1981239.

12. Theocharis SE, Skopelitou AS, Margeli AP, Pavlaki KJ, Kittas C. Proliferating cell nuclear antigen (PCNA) expression in regenerating rat liver after partial hepatectomy. Dig Dis Sci. 1994;39(2):245-52. PMID: 7906221.

13. Francavilla $A$, Panella $C$, Polimeno $L$, Giangaspero A, Mazzaferro V, Pan CE, Starzl TE. Hormonal and enzymatic parameters of hepatic regeneration in patients undergoing major liver resections. Hepatology. 1990;12(5):1134-8. doi: 10.1002/ hep.1840120510.

14. Ok E, Yilmaz Z, Akgün $H$, Sahin $H$. Use of olive oil based emulsions as an alternative to soybean oil based emulsions in total parenteral nutrition and their effects on liver regeneration following hepatic resection in rats. Ann Nutr Metab. 2003;47(5):221-7. PMID: 12748416.

15. Fausto N, Campbell JS, and Riehle KJ. Liver regeneration. Hepatology. 2006;43(2 Suppl 1):S45-53. PMID: 16447274.

16. Rüdiger, HA, Clavien PA. Tumor necrosis factor $\alpha$, but not Fas, mediates hepatocellular apoptosis in the murine ischemic liver. Gastroenterology. 2002;122(1):202-10. PMID: 11781294.

17. Abdel-Wahab AF, Al-Harizy WM. Propofol protects against ischemia/reperfusion injury associated with reduced apoptosis in rat liver. ISRN Anesthesiol. 2013;2013(2013). doi: $10.1155 / 2013 / 517478$.

18. Michalopoulos GK. Liver regeneration. J Cell Physiol. 2007;213(2):286-300. PMID: 17559071.

19. Liu Z, Sakamoto T, Ezure T, Yokomuro S, Murase N, Michalopoulos G, Demetris AJ. Interleukin-6, hepatocyte growth factor, and their receptors in biliary epithelial cells during a type iductular 
reaction in mice: Interactions between the periductal inflammatory and stromal cells and the biliary epithelium. Hepatology. 1998;28(5):1260-8. PMID: 9794910.

20. Hayashi H, Shimizu K, Tani T, Takamura H, Takeshita M, Nakamura K, Kayahara M. Effect of porto-systemic shunting on NOS expression after extended hepatectomy in rats. Hepatol Res. 2009;39(1):78-85. PMID: 18713274.

21. Hori N, Wiest R, Groszmann RJ. Enhanced release of nitric oxide in response to changes in flow and shear stress in the superior mesenteric arteries of portal hypertensive rats. Hepatology. 1998;28(6):1467-73. PMID: 9828208.

22. Wiest R, Shah V, Sessa WC, Groszmann RJ. NO overproduction by eNOS precedes hyperdynamic splanchnic circulation in portal hypertensive rats. Am J Physiol. 1999;276(4):G1043-51. PMID: 10198349.

23. Buga GM, Gold ME, Fukuto JM, Ignarro LJ. Shear stress-induced release of nitric oxide from endothelial cells grown on beads. Hypertension. 1991;17(2):187-93. PMID: 1991651.

24. Schoen JM, Wang HH, Minuk GY, Lautt WW. Shear stress-induced nitric oxide release triggers the liver regeneration cascade. Nitric Oxide. 2001;5(5):453-64. PMID: 11587560.

25. Wang LM, Tian XF, Song QY, Gao ZM, Luo FW, Yang CM. Expression and role of inducible nitric oxide synthase in ischemiareperfusion liver in rats. Hepatobiliary Pancreat Dis Int. 2003;2(2):252-8. PMID: 14599979.

26. Asakura H, Asamura R, Ontachi Y, Hayashi T, Yamazaki M, Morishita E, Nakao S. Selective inducible nitric oxide synthase inhibition attenuates organ dysfunction and elevated endothelin levels in LPS-induced DIC model rats. J Thromb Haemost. 2005;3(5):1050-5. PMID: 15869603.

27. Liu LM, Dubick MA. Hemorrhagic shockinduced vascular hyporeactivity in the rat: relationship to gene expression of nitric oxide synthase, endothelin-1, and select cytokines in corresponding organs. J Surg Res. 2005;125(2):128-36. PMID: 15854664.

28. Hsu CM, Wang JS, Liu CH, Chen LW. Kupffer cells protect liver from ischemiareperfusion injury by an inducible nitric oxide synthase-dependent mechanism. Shock. 2002;17(4):280-5. PMID: 11954827.

29. Wang $\mathrm{HH}$, Lautt WW. Evidence of nitric oxide, a flow-dependent factor, being a trigger of liver regeneration in rats. Can J Physiol Pharmacol. 1998;76(12):1072-9. PMID: 10326828.

30. Liu P, Xu B, Spokas E, Lai PS, Wong PY. Role of endogenous nitric oxide in TNF-[alpha] and IL-1 [beta] generation in hepatic ischemiareperfusion. Shock. 2000;13(3):217-23. PMID: 10718379.

31. Moulian N, Truffault F, Gaudry-Talarmain YM, Serraf A, Berrih-Aknin S. In vivo and in vitro apoptosis of human thymocytes are associated with nitrotyrosine formation. Blood. 2001;97(11):3521-30. PMID: 11369646.

32. Rai RM, Lee FYJ, Rosen $A$, Yang SQ, Lin $H Z$, Koteish A, Diehl AM. Impaired liver regeneration in inducible nitric oxide synthasedeficient mice. Proc Natl Acad Sci USA. 1998;95(23):13829-34. PMID: 9811886.

33. Inoue $\mathrm{Y}$, Tomiya $\mathrm{T}$, Yanase $\mathrm{M}$, Arai $\mathrm{M}$, Ikeda H, Tejima K, Fujiwara K. p53 may positively regulate hepatocyte proliferation in rats. Hepatology. 2002;36(2):336-44. PMID: 12143041

34. Dikmen B, Yagmurdur H, Akgul T, Astarci M, Ustun $\mathrm{H}$, Germiyanoglu C. Preventive effects of propofol and ketamine on renal injury in unilateral ureteral obstruction. J Anesth. 2010;24(1):73-80. PMID: 20069316.

35. Wang $H$, Xue $Z$, Wang $Q$, Feng $X$, Shen $Z$. Propofol protects hepatic L02 cells from hydrogen peroxide-induced apoptosis via activation of extracellular signalregulated kinases pathway. Anesth Analg. 2008;107(2):534-40. PMID: 18633031.

36. Budihardjo I, Oliver $H$, Lutter $M$, Luo X, Wang $X$. Biochemical pathways of caspase activation during apoptosis. Annu Rev Cell Dev Biol. 1999;15(1):269-90. PMID: 10611963.

37. Cory S, Huang DC, Adams J M. The Bcl-2 family: roles in cell survival and oncogenesis. Oncogene. 2003;22(53):8590-607. PMID: 14634621.

38. Yagmurdur $H$, Ayyildiz A, Karaguzel E, Akgul T, Ustun H, Germiyanoglu C. Propofol reduces nitric oxide-induced apoptosis in testicular ischemia-reperfusion injury by 
downregulating the expression of inducible nitric oxide synthase. Acta Anaesthesiol Scand. 2008;52(3):350-7. PMID: 18205898.

39. Shimizu $H$, Miyazaki M, Yoshioka S, Ito $H$, Nakagawa K, Ambiru S, Fukuda Y. Changes in hepatic venous oxygen saturation related to the extent of regeneration after partial hepatectomy in rats. Am J Surg. 1999;178(5):428-31. PMID: 10612545.

40. Mangnall D, Bird NC, Majeed AW. The molecular physiology of liver regeneration following partial hepatectomy. Liver Int. 2003;23(2):124-38. PMID: 12654135.

41.Osman ES, Khafagy HF, Samhan YM, Hassan $M M$, El-Shanawany FM, Fathallah AR, El-Fandy GG. In vivo effects of different anesthetic agents on apoptosis. Korean J Anesthesiol. 2012;63(1):18-24. PMID: 22870360.

42. Li CY, Chou TC, Wong CS, Ho ST, Wu CC, Yen $\mathrm{MH}$, Ding YA. Ketamine inhibits nitric oxide synthase in lipopolysaccharide-treated rat alveolar macrophages. Can J Anaesth. 1997;44(9):989-95. PMID: 9305563.

43. Shibakawa YS, Sasaki Y, Goshima Y, Echigo $\mathrm{N}$, Kamiya $\mathrm{Y}$, Kurahashi K, Yamada Y, Andoh T. Effects of ketamine and propofol on inflammatory responses of primary glial cell cultures stimulated with lipopolysaccharide. $\mathrm{Br} J$ Anaesth. 2005;95(6):803-10. PMID: 16227338.

\section{Correspondence:}

Assistant Professor Kenan Binnetoglu

Kafkas University

Department of General Surgery

School of Medicine (36000)

Kars Turkey

Phone: (+) 905469382102

kenanbinnet@hotmail.com

Received: Jan 15, 2017

Review: Mar 18, 2017

Accepted: Apr 19, 2017
Conflict of interest: none

Financial source: none
${ }^{1}$ Research performed at Animal Investigation Committee, Ministry of Health Ankara Research and Training Hospital, Turkey. 